\title{
Exploring the Knowledge Levels, Attitudes and Beliefs of Patients' Relatives Towards Organ Donation in the Intensive Care Units of Two Majors Hospitals in Trinidad
}

\author{
Philip Onuoha ${ }^{1}$, Gloria Ramdeen-Mootoo ${ }^{1}$, Ria Edwards ${ }^{1}$, Rita Gobin ${ }^{1}$, Dionne McConney ${ }^{1}$, Alicea \\ Greene-Nicholas ${ }^{1}$, Dianne Ramoo ${ }^{1} \&$ Vanessa Young ${ }^{1}$ \\ ${ }^{1}$ The UWI School of Nursing, The University of the West Indies, St. Augustine, Trinidad and Tobago \\ Correspondence: Philip Onuoha, The UWI School of Nursing, The University of the West Indies, St. Augustine, \\ Trinidad and Tobago. Tel: 868-225-1026 Ext.3029. E-mail: Philip.onuoha@sta.uwi.edu
}

Received: March 6, 2020 Accepted: June 5, 2020 Online Published: June 30, 2020

doi:10.5539/gjhs.v12n9p15 URL: https://doi.org/10.5539/gjhs.v12n9p15

\begin{abstract}
Purpose: To ascertain the Knowledge levels, Attitudes and Beliefs towards Organ Donation by Relatives of Patients in the Intensive Care Unit at two Tertiary Care Hospitals in Trinidad.

Methods: A quantitative descriptive study in which the researchers'-designed and pretested self-administered questionnaire was used on a sample of 133 randomly selected patients' relatives from two main intensive care hospitals units of Trinidad. The respondents were requested to give their consent after necessary ethical approval was received. Data entry was done manually but the analysis was done with the SPSS version 12 programme. Results were presented as frequencies.

Results: Demographic characteristics indicate that most were females, of African ethnicity, and Christianity as their main religion. The majority of participants had high level of knowledge $(69.2 \%)$ while $57.9 \%$ of them had unfavourable attitude towards organ donation. Most (86.5\%) had positive belief. It also showed that the respondents' knowledge towards organ donation is significantly related to their age and religion, $(\mathrm{P} \leq, 0.05)$ while their attitudes are significantly related to their gender and ethnicity $(\mathrm{p} \leq 0.05)$. Their belief is only significantly associated with their marital status.
\end{abstract}

Discussion: The findings of the study were compared with previous studies and the researchers showed how the relevant theories that guided the study were used to explain the findings.

Conclusion: Based on the findings, the researchers made a number of recommendations particularly related to public education in attempt to address the attitudes of the public related to organ donation in Trinidad and Tobago.

Keywords: organ donation, Caribbean, knowledge, attitudes and belief, health care

\section{Introduction}

\subsection{Background}

The practice of organ donation is an effective way of prolonging life. Although the access of patients to organ donation varies given their national situations, the cost of health care, the level of technical capacity and the availability of organs, the increasing yearly statistics of prospective recipients shows that persons are interested and accessing this service (WHO, 2016).

Cleveland Clinic (Cleveland Clinic, 2016) opines that organ donation is the donation of biological tissue or an organ of the human body, from a living or deceased person to a living recipient in need. This transplantation is necessary because the recipient's organ has failed or has been damaged by disease or injury, and is often the only treatment for end stage organ failure, such as liver, kidney and heart failure. Organ transplantation is now seen as a preferred treatment modality for end-stage organ disease, and offers a better quality of life with better survival benefits (Cleveland Clinic, 2016).

In countries such as Spain, France, Sweden, and across Europe, organ donation is openly discussed with every potential donor or their relatives, as is, the accepted practice (BBC News, 2015). It has become one of the great advances in modern medicine. In these countries however, even in these countries the need for organ donors is 
much greater than the number of people who actually donate. Statistics shows that every day in the United States 18 people die waiting for an organ to be donated to them and more than 100,000 men, women, and children await life-saving organ transplants (Cleveland Clinic, 2016).

In the Caribbean nation states, such as Jamaica, Grenada and Antigua, the practice of organ donation has not fully permeated the societies (Soyibo, 2012). Despite the existence of National Organ Transplant Unit (NOTU) in Trinidad and Tobago, organ donation numbers are still not encouraging. It remains a topic for national discussion, since relatives as well as potential donors continue to be apprehensive towards the advancement of this practice and the subject of organ donation is still seen as taboo. In many Caribbean cultures, persons are hesitant to remove necrotic tissues that may affect their health status, it becomes even harder to persuade individuals to donate their organs. Soyibo (2012) asserts that they should go back to their Creator just as they came, hence we surmise that their attitudes, beliefs and knowledge may contribute to their unwillingness to this practice. In Trinidad and Tobago the demand for organs for transplantation continues to exceed the supply. Further, due to the high prevalence of chronic diseases among the population, there is an increased number of individuals living with organ failure (Baal, 2011) while Pan American Health Association (PAHO, 2012), indicates that chronic non communicable diseases (CNCD's) are collectively the leading cause of death in Trinidad and Tobago.

In 2011 Ministry of Health, Trinidad and Tobago, (2016) estimated that over 500 individuals were in need of kidney transplant and that over 900 persons are on the waiting list. Crime related deaths in Trinidad and Tobago in 2015 was 420 (Overseas Security Advisory Council for the United States Department of State Bureau of Diplomatic Security, 2016), while Arrive Alive (2015) informed that Trinidad and Tobago road fatalities numbered at 147 for the year 2015. We believe that these numbers represent the loss of viable organs that could have been beneficial to those recipients on the waiting list. This is in spite of the actions of National Organ Transplant Unit (NOTU) and their intervention.

The reality is that there is an almost universal shortage of donors (Rudge, 2012). The patients' families play major a role in increasing the number of organs needed to meet the demands by the population. Families' avoidance of giving consent for organ donation is an obstacle in this regard (Tahrekhani, 2016). In Iran, Yousefi, Roshani and Nazari (2014), indicated that the decision to donate an organ is a very tough one for some families. It indicated that certain factors including humanistic desires, immortality, culture making challenges, the satisfaction levels, the eternal honour of the deceased and the assurance of the relatives, all play different role in the relatives' willingness to donate.

It is not clear what the situation is in Trinidad and Tobago as the authors are not aware of any study that attempted to determine what contributes to this lack of desire to donate organ. We envisage that ascertaining whether the knowledge levels of patients' relatives are high or not, if their beliefs are positive or negative and if their attitudes are favourable or not towards organ donation will go a long way at determining what may be the contributory factors to the problem of scarcity of organs for many needy patients despite the numerous violent deaths that occur in the Island state.

\subsection{Objectives}

The specific objectives are to:

1. To determine the levels of knowledge of relatives of patients in the ICU on organ donation.

2. To ascertain if the beliefs of the relatives of patients in the ICU on organ donation are positive of negative.

3. To ascertain if attitudes of the patients relatives are favourable or unfavourable to organ donation.

4. To determine if the respondents' (a) levels of knowledge, (b) beliefs and (c) attitudes are significantly associated with their demographic characteristics.

\subsection{Research Questions}

1. What are the knowledge levels of the patients relatives regarding organ donation

2. Are the beliefs of the patients' relatives favourable or not regarding organ donation

3. Do the relatives of patients in ICUs in Trinidad have positive or negative attitudes toward organ donation?

4. Are the knowledge levels, attitudes and beliefs of the patients relatives at the ICU related to the demographic characteristics?

\section{Adapting the Theory of Reasoned Action and the Theory of Planned Behaviour to underpin the study}

The nature and relationship of the multiple factors that affect a range of health-related behaviours have led to the 
development of many theories (Glanz, Rimer and Viswanath, 2008). Two of such theories are the Theory of Planned Behaviour (TPB) and the Theory of Reasoned Action (TRA). Humans behave in particular ways because of multiple influences from biological characteristics, environment, education and culture. Our study seeks to understand the relationship between knowledge, attitudes and beliefs of patients' relatives in the ICU at the two major tertiary care hospitals in the Island of Trinidad and their willingness to donate. In effect, it seeks to explain the extent these variables may play a part where the patients' relatives are related to organ donation.

Both theories were founded on specific assumptions including that there was a causal chain that links behavioural beliefs, and normative beliefs to behaviour through attitudes and subjective norms. Both theories also focus on constructs that are concerned with individual motivational factors as determinants of the likelihood of performing a specific behaviour. Finally, they provide a systematic method of identifying those issues that are most important to a person's decision about performing specific behaviours (Glanz et al., 2008). Since these theories came out of a need to understand the relationship between attitudes and behaviour (for example the knowledge attitudes and beliefs of patient's relative towards organ donation), we believe their application to this study is appropriate.

The TRA was developed by Fishbein (1967) to better understand relationships between attitudes, intention and behaviours. Dillard \& Pfau (2002) states, "the individual's intention to perform given behaviours is dependent on attitudes towards the behaviour and their subjective norms associated with the behaviour and determined by the individual's beliefs about outcomes or attributes of performing the behaviour" (p.260). Thus, a person who holds strong beliefs that positively valued outcomes will result from performing the behaviour will have a positive attitude towards the behaviour. This can be applied to the process of organ donation for example where relatives who possess adequate knowledge, positive attitudes and beliefs towards organ donation would most likely positively consent to the process of organ donation.

The TRA considers the behavioural intention which affects behaviour. In this context, the theoretical framework is relevant to the research study as it would systematically identify the effect of the knowledge, attitudes and beliefs of patient's relatives towards organ donation in the ICU in two of the major hospitals in Trinidad and Tobago. It offers a framework for deciphering a relative's actions, whereby interventions can then be designed to target these beliefs leading to a change in intention and behaviour. In this context that refers to the patients' relatives' (knowledge base and attitudes); which when identified, measured and combined with their beliefs on the issue of organ donation would reveal the reasons that motivate the behaviour of interest, which are, consenting to donate their relatives' organs (Glanz et al., 2008).

The TPB developed by Ajzen in 1988, is an extension of the TRA. It includes an additional construct concerned with perceived control over performance of the behaviour. It asserts that a person will expend more effort to perform behaviour when his/her perception of behavioural control is high. Ajzen, (1991) states 'TPB is designed to account for the range of personal and social influences that may impact on people's decision making' (p.189).

TPB distinguishes between these three types of beliefs: behavioural, normative and control. According to Ajzen (1991), behavioural beliefs link the behaviour of interest to expected outcome which is belief that the behaviour will produce a given outcome. Normative beliefs refer to the supposed behavioural expectations of individuals or groups about whether or not significant people in their life would approve or disapprove of the behaviour and their motivation to obey with these expectations. Control beliefs on the other hand refer to an individual's belief that he or she possesses the necessary resources, skills, and opportunities to aid or inhibit performance of behaviour. Thus, the more favourable the attitude and the subjective norm, and the greater the perceived control, the stronger the person's intention to perform the behaviour in question should be (Hyde and White, 2009).

Thus we believe that the TRA and TPB are appropriate theoretical models that can be used to identify behaviour beliefs, normative beliefs and control beliefs that are relevant to the particular behaviour of the population under investigation (Glanz et al., 2008). These models have been used successfully to predict people's intentions and behaviours across the context of organ donation with varying results (Rocheleau, 2013).

\section{Research Methodology}

\subsection{Design}

A descriptive design was employed in the execution of the study (Polit and Beck, 2014). We investigated the issues of levels of knowledge, beliefs and attitudes of respondents towards organ donation in Trinidad.

\subsection{Population/Sample}

Patients' relatives in the Intensive Care Unit (ICU) Departments at the Port of Spain General Hospital (POSGH) and San Fernando General Hospital (SFGH) in Trinidad were studied. These were those who are related by blood 
or marriage, or who are the legal guardians of the patients admitted to the ICUs. This population was chosen because many patients in the ICU may have been identified as potential organ donors, but the relatives tend to show reluctance towards the donation of their relatives' organs. With 9- and 6-bedded capacities at the POSGH and SFGH respectively, we estimated a sample of 90 and 60 respectively totalling 150 respondents. However, 133 representing $88.7 \%$ of the respondents consented and therefore were recruited for the study at 81 and 42 for POSGH and SFGH respectively.

\subsection{Ethical Considerations}

We received ethical approval from the University of the West Indies Ethics Committee, as well as the Ethics committees of the North West Regional Health Authority (NWRHA) and South West Regional Health Authority (SWRHA) prior to any data collection.

\subsection{Instrument}

Researchers'-designed questionnaire was used for data collection. The instrument consisted of Likert Scale type questions. The questionnaire was constructed in four sections, comprising a total of 29 questions. Section A consisted of 7 questions related to demographic data, section B consisted of 11 questions related to relative's knowledge on organ donation, section $\mathrm{C}$ consisted of 4 questions to enquire the beliefs of relatives as it relates to organ donation, and section D consisted of 7 questions to determine the attitudes of relatives as it relates to organ donation. The instrument was pre-tested and adjudged to have the face and content validity.

\subsection{Data Analysis}

The data was collated manually, but analysed with the SPSS version 20. Descriptive Frequency tables were generated in response to objectives 1 to 3, while ANOVA tests were carried out to determine whether or not there are relationships among the knowledge levels, attitudes, and beliefs of the respondents and the respondents' selected demographic characteristics.

\section{Results}

\subsection{Socio-Demographic Characteristics}

The result is presented according to the research questions. Table 1 illustrates the distribution of the research participants according to their socio-demographic variables. It shows that majority of the respondents were within the age group 28-37 (39.1\%) followed by the age group 38-47 (30.1\%). It also shows that the respondents were mostly females (67.4\%), of African ethnicity (43.6\%), Christians (63.9\%) and married (35.3\%).

To answer research questions 1, 2 and 3; Figure 1 illustrates the results. In the figure, it can be seen that $69.2 \%$ of the respondents have adequate to high knowledge levels. Also $86.5 \%$ of the respondents' have positive belief while $57.9 \%$ of them have unfavourable attitudes towards organ donation.

The answer to research question 4 was illustrated in Table 2 that is indicating whether or not there is a relationship between (a) knowledge level of the respondents, (b) their attitudes and (c) their beliefs and the socio-demographic characteristics namely: (i) age, (ii) gender, (iii) ethnicity, (iv) religion, and (v) Marital Status. The result shows that the respondents' levels of knowledge is associated with their age $(\mathrm{p} \leq .035)$ and religion $(\mathrm{p} \leq .015)$. It also shows that the subjects' attitudes are significantly related with their gender $(\mathrm{p} \leq .030)$ while their beliefs are significantly associated with their marital status ( $\mathrm{p} \leq .005)$.

Table 1. Sociodemographic data-N=133

\begin{tabular}{lll}
\hline Demographic variables & f & \% \\
\hline Age & & 13.5 \\
$18-27$ & 18 & 39.1 \\
$28-37$ & 52 & 30.1 \\
$38-47$ & 40 & 17.3 \\
48 and over & 23 & \\
\hline
\end{tabular}




\begin{tabular}{|c|c|c|}
\hline \multicolumn{3}{|l|}{ Gender } \\
\hline Male & 48 & 36.1 \\
\hline Female & 83 & 62.4 \\
\hline Other & 2 & 1.5 \\
\hline \multicolumn{3}{|l|}{ Ethnicity } \\
\hline African & 58 & 43.6 \\
\hline East Indian & 39 & 29.3 \\
\hline Chinese & 9 & 6.8 \\
\hline Mixed & 24 & 18.0 \\
\hline Other & 3 & 2.3 \\
\hline \multicolumn{3}{|l|}{ Religion } \\
\hline Hindu & 28 & 21.1 \\
\hline Muslim & 15 & 11.3 \\
\hline Christian & 85 & 63.9 \\
\hline Other & 5 & 3.8 \\
\hline \multicolumn{3}{|l|}{ Marital Status } \\
\hline Single & 46 & 34.6 \\
\hline Common law & 20 & 15.0 \\
\hline Married & 47 & 35.3 \\
\hline Separated & 5 & 3.8 \\
\hline Divorce & 8 & 6.0 \\
\hline Widowed & 6 & 4.5 \\
\hline Other & 1 & .8 \\
\hline
\end{tabular}

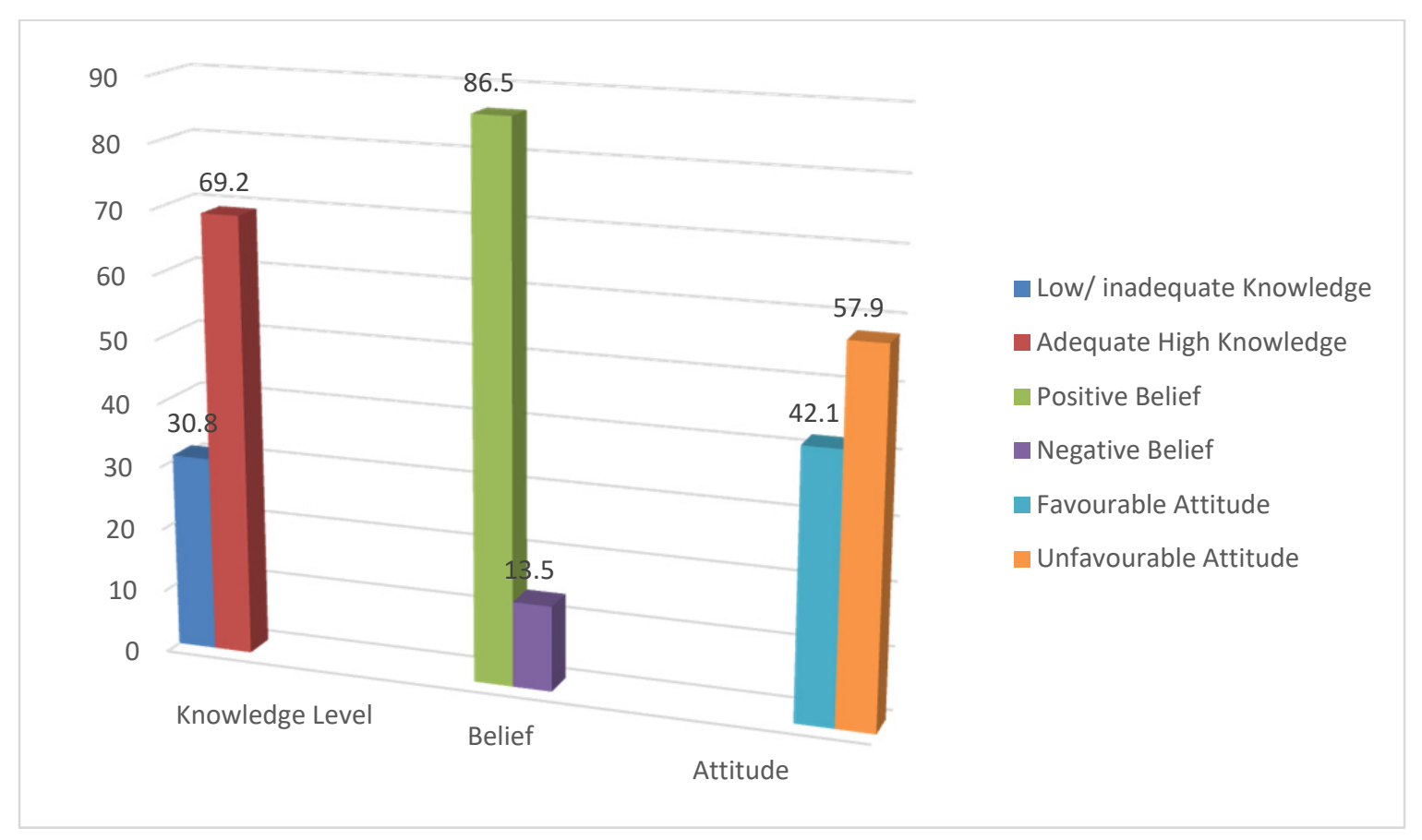

Figure 1. Knowledge Levels, belief and attitudes of partiticipants towards organ donation 
Table 2. ANOVA Related to Respondents' Selected Socio demographic variables and their knowledge level, attitude and beliefs towards organ Donation

\begin{tabular}{|c|c|c|c|}
\hline & Knowledge & Attitude & Beliefs \\
\hline Age & 0.035* & -0.242 & 0.147 \\
\hline Gender & 0.189 & -0.030 * & 0.079 \\
\hline Ethnicity & -0.062 & $-0.046^{*}$ & -0.150 \\
\hline Religion & $.015 *$ & -.092 & 0.205 \\
\hline Marital Status & 0.067 & -0.148 & $-0.005^{*}$ \\
\hline
\end{tabular}

$* P \leq 0.05$ significant level.

\section{Discussion}

The main findings of this study suggest that the knowledge levels of the respondents are generally high, and so is their positive belief in organ donation. However, they have higher unfavourable attitudes than their favourable attitudes.

Cumulatively, respondents with medium and high level of knowledge represented $69.2 \%$ of the population. This showed that generally there was a fairly good awareness level on the issue of organ donation. This supports the National Survey of Organ Donation Attitudes and Behaviours (2012), Jacob, Dana, Robinson, Perryman, and Thompson, (2008) that reported general high knowledge levels on the subject. On the attitudes, Zimberan (2015), had indicated that body image is becoming a significant reason for not engaging in organ donation which perhaps explains the result that $57.9 \%$ of the respondents have unfavourable attitudes to organ donation. This however is inconformity with a number of other scholars' findings. For example, Mithra et al. (2013) indicated that although there is high level of awareness about organ donation, there are also a high proportion of the participants who do not have positive attitudes towards organ donation in south India. This study found that belief in organ donation is positive thus confirming findings from any other studies namely Zimberan (2015), Falomir-Pichastor, Berent and Pereira, (2010), Zhang et al. (2007), and El-Shoubaki (2005).

Overall, this study has shown that the patients' relatives at the 2 major general hospitals have high knowledge, and positive beliefs but did not have favourable attitudes. From the theoretical background, humans behave in particular ways because of multiple influences from biological characteristics, environment, education and culture. We note that the TRA and TPB had explained how the concepts such as knowledge, attitude and beliefs regarding organ donation could be motivational factors which act as determinants of the likelihood of performing their specific behaviour such as decision to donate organ. We are of the view that all these 3 concepts are necessary when determining behaviour and posit that when any or a combination of any of the 3 is low, the effect will affect the degree of the expected behaviour. We believe that this is one of the extensions of the theories as explained by Glanz et al., (2008). Thus, in this study as the attitudes of the patients' relatives remain low, irrespective of the knowledge levels or beliefs, we expect that the decision of the patients' relatives at the 2 hospitals to donate organs will be negatively affected. This conclusion further agrees with other authors' findings (Zhang et al., 2007; El-Shoubaki, 2005; Oliver et al., 2012; Irving, 2012)

\section{Recommendations}

We recommend an exploration of this attitudinal barriers to organ donation to include personal experiences on this sensitive topic of organ donation with an aim to influencing changes in personal attitude, values and opinion as they relate to the need for organ donation.

In Trinidad and Tobago, we recommend that the way forward is to create an enabling environment that will assist individuals and the public to change their attitude towards the topic of organ donation.

\section{Conclusion}

Our study comes at a time in Trinidad when organ donation is still in its teething stage despite the establishment of NOTU in 2006. The study identified factors such as knowledge, attitudes and beliefs of the researched population towards organ donation and showed that its attitude towards donation was not a favourable one. However, the way forward for the deceased donation programme is to create an enabling environment in the public that may change their general attitude towards it. 


\section{Limitations}

We note that this study has some inherent limitation issues including but not limited to use of only 2 hospitals in

Trinidad to the exclusion of the twin Island, Tobago, the manner of sampling patients' relatives when their loved ones were in critical situation, and the general sensitive nature of the topic under investigation. The investigators however, underwent some training in Ethics, a requirement for granting ethics approval by the University of the West Indies, were very diligent, used all necessary skills and expertise in data collection, treatment, analysis and interpretation. We still recommend more inclusive studies before findings can be generalised to the population of Trinidad and Tobago.

\section{Competing Interests Statement}

None.

\section{References}

Ajzen, I. (1991). The Theory of Planned Behaviour. Organizational behaviour and human decision processes, 50(2), 179-211. https://doi.org/10.1016/0749-5978(91)90020-T

Arrive Alive Trinidad and Tobago (2015). Statistics-Arrive Alive. Retrieved from www.arrivealivett.com/statistics/

Baal, R. (2011). Trinidad and Tobago Newsday. TT dying from chronic diseases. Retrieved from http://www.newsday.co.tt/news/0,147391.html

Bapat, U., Kedlaya, P. G., \& Gokulnath. (2010). Organ donation, awareness, attitudes and beliefs among post graduate medical students. Saudi J Kidney Dis Transpl, 21, 174-180.

British Broadcasting Communications News (2015). Organ donation: Law change not enough. Retrieved from http://www.bbc.com/news/uk-wales-34932958.

Burns, N., \& Groves, S. K. (2011). Clarifying Measurement and Data Collection in Quantitative Research. Understanding Nursing Research: Building an Evidenced Based Practice (5th ed., p. 326). Missouri: Saunders Elsevier.

Cambridge Dictionary (2016). Retrieved from http://ictionary.cambridge.org/dictionary/english

Cleveland Clinic (2016). Organ Donation Facts and Information on Organ Transplants.

Coad, L., Carter, N., \& Ling, J. (2013). Attitudes of young adults from the UK towards organ donation and transplantation. Transplantation research, 2(1), 9. https://doi.org/10.1186/2047-1440-2-9

Davis, C., \& Randhawa, G. (2004). Awareness and Attitudes toward organ donation and transplantation among the black Caribbean and black African population. Retrieved from https://www.researchgate.net/.../7181174_The_influence_of_religion_on_organdonation

Dillard, J. P., \& Pfau, M. (2002). The Persuasion Handbook: Developments in Theory and Practice ( ${ }^{\text {nd }}$ ed.). Thousand Oaks, California 91320: Sage Publications, Inc. E-journal.um.edu.my. Holy Qur'an, Surat Al-Maeda Retrieved July 3, 2017, from http://www.bing.com/cr?

El-Shoubaki, H., \& Bener, A. (2008). Public knowledge and attitudes toward organ donation and transplantation. Retrieved from www.ncbi.nlm.nih.gov/pubmed/15964321

Falomir-Pichastor, J. M., Berent, J. A., \& Pereira, A. (2013). Social psychological factors of post-mortem organ donation: a theoretical review of determinants and promotion strategies. Health Psychology Review, 7(2), 202-247. https://doi.org/10.1080/17437199.2011.570516

Glanz, K., Rimer, B. K., \& Viswanath, K. (2008). Health Behaviour and Health Education: Theory, Research, and Practice ( $4^{\text {th }}$ ed.). San Francisco, CA 94103-1741: Jossey Bass.

Hassaballah, A. M. (1996). Definition of death, organ donation and interruption of treatment in Islam. Nephrology Dialysis Transplantation, 11(6), 964-965. $\quad$ Retrieved from https://scholar.google.com/citations?user=XwLRUy4AAAAJ

Hyde, M. K., \& White, K. M. (2009). To Be a Donor or Not to Be? Applying an Extended Theory of Planned Behaviour to Predict Posthumous Organ Donation Intentions. Journal of Applied Social Psychology, 39, 880-900. https://doi.org/10.1111/j.1559-1816.2009.00464.x

Irving, M. J., Tong, A., Jan, S., Cass, A., Chadban, S., Allen, R. D., ... \& Howard, K. (2012). Community attitudes to deceased organ donation: a focus group study. Transplantation, 93(10), 1064-1069. Retrieved from 
https://www.ncbi.nlm.nih.gov/pubmed/22510575

Irving, M. J., Tong, A., Jan, S., Cass, A., Rose, J., Chadban, S., ... \& Howard, K. (2012). Factors that influence the decision to be an organ donor: a systematic review of the qualitative literature. Nephrology Dialysis Transplantation, 27(6), 2526-2533. Retrieved from https://www.ncbi.nlm.nih.gov/pubmed/22193049

Jacob, R. K., Dana, A., Robinson, H. Z., Perryman, J. P., \& Thompson, N. (2008). Understanding the Relationship between Knowledge and African Americans' Donation Decision-Making. https://doi.org/10.1016/j.pec.2007.09.017

McClure, R. D. (2002). Common Data Collection Strategies Effective in Qualitative Studies Using Action Research in Technical/Operational Training Programs.

Ministry of Health of Trinidad and Tobago (2016). Becoming an Organ Donor. Retrieved on 31.10.2016 from http://www.health.gov.tt/sitepages/default.aspx?id=109.

Mithra, P., Ravindra, P., Unnikrishnan, B., Rekha, T., Kanchan, T., Kumar, N., ... \& Divyavaraprasad, K. (2013). Perceptions and attitudes towards organ donation among people seeking healthcare in tertiary care centers of coastal South India. Indian journal of palliative care, 19(2), 83. https://doi.org/10.4103/0973-1075.116701

Mosby's Medical Dictionary. (2009). Cadaveric Renal Transplant. ( $8^{\text {th }}$ ed.). Retrieved from http://medical dictionary.thefreedictionary.com/cadaveric + renal + transplant

National Organ Transplant Unit. (NOTU, 2016). National Organ Donation Programme. National Survey of Organ Donation Attitudes and Behaviour. (2012). Retrieved from https://www.organdonor.gov/dtcp/nationalsurveyorgandonation.pdf

Odusanya, O. O., \& Ladipo, C. O. (2006). Organ donation: knowledge, attitudes, and practice in Lagos, Nigeria. Artificial organs, 30(8), 626-629. https://doi.org/10.1111/j.1525-1594.2006.00272.x

Oliver, M., Woywodt, A., Ahmed, A., \& Saif, I. (2011). Organ donation, transplantation and religion. https://doi.org/10.1093/ndt/gfq628

Optimisa Research. (2013). Understanding current attitudes and behaviours towards organ donation within England. NHS Blood and Transplant (NHSBT). Retrieved from www.nhsbt.nhs.uk/to2020/the-strategy/.../nhsbt-organ-donor-report-140813.pdf

Organ Procurement and Transplantation Network. (n.d.). Retrieved July 02, 2017, from https://optn.transplant.hrsa.gov/

Pan American Health Organization (PAHO, 2012). Organ Transplantation and the development of a Deceased Organ Transplantation Network. Retrieved from www.paho.org/trt/index.php?option=com_content\&limitstart=40.

Polit, D. F., \& Beck, C. T., (2014). Essentials of Nursing Research, Appraising Evidence for Nursing Practice. ( $8^{\text {th }}$ Ed). Wolters Kluwer Health/ Lippincott Williams and Wilkins: New Delhi.

Pouraghaei, M., Tagizadieh, M., Tagizadieh, A., Moharamzadeh, P., Esfahanian, S., \& Nia, K. S. (2015). Knowledge and attitude regarding organ donation among relatives of patients referred to the emergency department. Emergency, 3(1), 33. Retrieved November 21, 2016, from https://www.ncbi.nlm.nih.gov/pmc/articles/PMC4614608/

Religions-Christianity: Organ donation. (2009, August 03). Retrieved July 02, 2017, from http://www.bbc.co.uk/religion/religions/christianity/christianethics/organs.shtml

Roberts, L., Ali, A., \& Ahmed, F. (2012). Living donor kidney transplantation: the donor profile in Trinidad and Tobago. West Indian Medical Journal. Retrieved from http://caribbean.scielo.org/scielo.php?pid=S0043-31442012000300016\&script=sci_arttext

Rocheleau, C. A. (2013). Organ donation intentions and behaviours: application and extension of the theory of planned behaviour. J Appl Soc Psychol, 43, 201-213. https://doi.org/10.1111/j.155

Rudge, C. (2012). International practices of organ donation. Retrieved from http://bja.oxfordjournals.org/content/108/suppl_1/i48.long.

Saleem, T., Ishaque, S., Habib, N., Hussain, S. S., Jawed, A., Khan, A. A., ... \& Jehan, I. (2009). Knowledge, attitudes and practices survey on organ donation among a selected adult population of Pakistan. BMC medical ethics, 10(1), 5. https://doi.org/10.1186/1472-6939-10-5 
Saleem, T. (2015). Knowledge, attitudes and practices survey on organ donation among a selected adult population of Pakistan. Retrieved from www.ncbi.nlm.nih.gov

Share and discover research. (n.d.). Retrieved July 02, 2017, from https://www.researchgate.net/...Financial_Incentives...Organ_Donation.../55de4d4b08ae

Shilubane, H. (2009). Research Methodology. Retrieved from http://uir.unisa.ac.za/bitstream/handle/10500/1450/04chapter3.pdf?sequence=59-1816.2012.00998

Shimazono, Y. (2007). The state of the international organ trade: a provisional picture based on integration of available information. Bulletin of the World Health Organization, 85, 901-980. https://doi.org/10.2471/BLT.06.039370

Soyibo, A. K. (2012). Renal disease in the Caribbean: the disease of the past, present and future. Retrieved from http://caribbean.scielo.org/scielo.php?script=sci_arttext\&pid=S0043-31442012000400022

Techopedia (2016). Statistical Package for the Social Sciences. Retrieved from https://www.techopedia.com/definition/12401/statistical-package-for-the-social-sciences-spss

United States Department of Health and Human Services Health Resources and Services Administration Healthcare Systems Bureau Division of Transplantation. (2012). National Survey of Organ Donation Attitudes and Behaviours. Retrieved from www.organdonor.gov/dtcp/nationalsurveyorgandonation.pdf.

Wakefield, C. E., Watts, K. J., Homewood, J., Meiser, B., \& Siminoff, L. A. (2010). Attitudes toward organ donation and donor behaviour: a review of the international literature. Retrieved from https://doi.org/10.7182/prtr.20.4.p54651601pg80183

Wood, M. J., \& Ross-Kerr, J. C. (2011). Basic Steps in Planning Nursing Research: From Question to Proposal. ( $7^{\text {th }}$ Ed.). Canada: Jones and Bartlett Publishers.

World Health Organisation (WHO, 2016). The state of the international organ trade: a provisional picture based on integration of available information. Retrieved from http://www.who.int/bulletin/volumes/85/12/06-039370/en/.

Yousefi, H., Roshani, A., \& Nazari, F. (2014). Experiences of the families concerning organ donation of a family member with brain death. Retrieved from https://www.ncbi.nlm.nih.gov/pmc/articles/PMC4

Yuen, C. C., Burton, W., Chiraseveenuprapund, P., Elmore, E., Wong, S., Ozuah, P., \& Mulvihill, M. (1998). Attitudes and beliefs about organ donation among different racial groups. Journal National Medicine Association. PMCID: PMC2608302.

Zhang, L., Li, Y., Zhou, J., Miao, X., Wang, G., Li, D., ... \& Li, J. (2007). Knowledge and willingness toward living organ donation. Retrieved from https://www.ncbi.nlm.nih.gov/pubmed/17580127.

Zimbrean, P. C. (2015). Body image in transplant recipients and living organ donors. Current opinion in organ transplantation, 20(2), 198-210. https://doi.org/10.1097/MOT.0000000000000165

Zuckerman, M., Silberman, J., \& Hall, J. A. (2013). The Relation Between Intelligence and Religiosity: A Meta-Analysis and Some Proposed Explanations. Personality and Social Psychology Review. https://doi.org/10.1177/1088868313497266

\section{Copyrights}

Copyright for this article is retained by the author(s), with first publication rights granted to the journal.

This is an open-access article distributed under the terms and conditions of the Creative Commons Attribution license (http://creativecommons.org/licenses/by/4.0/). 